\title{
Controlled Vocabulary
}

National Cancer Institute

\section{Source}

National Cancer Institute. Controlled Vocabulary. NCI Thesaurus. Code C48697.

A set of terms that are selected and defined based on the requirements set out by the user group, usually a set of vocabulary is chosen to promote consistency across data collection projects. 